\title{
Evaluating the Influence of Preflaring with Ultrasonic Tip and Rotary File on Determination of Initial Apical File - An In Vitro Study
}

\author{
Kakollu Sudha, Ediga Sandhyarani, Bhupathi Sravanthi Yadav, Kalgotla Aparna, \\ Mekala Ashwini, Gudivada Sujan Sushma \\ Department of Conservative Dentistry and Endodontics, Government Dental College and Hospital, Vijayawada, Andhra Pradesh, India
}

Email for correspondence: $2406 \mathrm{esr} @ g m a i l . c o m$

\begin{abstract}
Background: Success of endodontic treatment relies on accurate determination of working length (WL) and adequate enlargement of the root canal. One standard method of deciding the size of apical preparation is to first determine the pre-operative canal diameter by passing consequently larger instrument to the WL until one binds. Importance of preflaring before initial apical file (IAF) determination has been confirmed by different studies. Aims and Objectives: This study aims to evaluate the influence of preflaring with ultrasonic tip and rotary file on determination of IAF - an in vitro study. Materials and Methods: Thirty extracted human molar teeth were randomly divided into three groups $(n=10)$ : control group (Group-1); Protaper group (Group-2); and diamond ultrasonic tip group (Group-3). Patency was maintained and WL was established. All instruments were used according to the manufacturer's instructions. Stereomicroscopic images of apical section of root were taken to determine the discrepancies in diameters of files and root canal. ProPlus software (USA) was used to determine the diameter of the root canal. ANOVA test and post hoc tests - multiple comparisons were used for statistical analysis. Results: Canals preflared with ultrasonic tips which showed the best results. Control group, i.e., the canals with no preflaring showed the maximum discrepancy between the IAF diameter and apical canal diameter. Conclusion: Preflaring plays an important role in reducing the discrepancy between IAF diameter and apical canal diameter.
\end{abstract}

Key words: Apical canal diameter, endodontic working width, file size, initial apical file, molar teeth, preflaring

\section{INTRODUCTION}

Success of endodontic treatment relies on accurate determination of working length (WL) and adequate enlargement of the root canal. ${ }^{[1]}$ One recommended approach is to enlarge the apical root canal to three sizes larger than the first file to bind (Walton and Torabinejad, 1996; Weine, 1996). The concept behind this approach is that the first file to bind reflects the diameter of the apical canal. ${ }^{[2]}$

\begin{tabular}{|c|c|}
\hline Quick Response Co & Article Info: \\
\hline & doi: 10.5866/2019.11.10074 \\
\hline & $\begin{array}{l}\text { Received: 05-07-2019 } \\
\text { Revised: 07-08-2019 } \\
\text { Accepted: } 12-08-2019 \\
\text { Available Online: 01-10-2019, (www. } \\
\text { nacd.in) @ NAD, 2019 - All rights reserved }\end{array}$ \\
\hline
\end{tabular}

However, there is no evidence that the instrument that binds first does reflect the diameter of canal in the apical region. It was demonstrated that sensation of the file fit does not necessarily occur due to contact at the apex as assumed but may instead be the result of interference in coronal and middle thirds of the canal. ${ }^{[3]}$

One standard method of deciding the size of apical preparation is to first determine the preoperative canal diameter by passing consequently larger instrument to the WL until one binds. This initial file estimation is referred to as initial working width.

There are many factors such as irregularity of walls and curvature of the root which affect initial working width determination. ${ }^{[4]}$ To minimize the influence of these affecting factors, early coronal flaring is recommended. 
Importance of preflaring before initial apical file (IAF) determination has been confirmed by different studies. Preflaring can be done with either manual or rotary instruments. The previous studies have investigated the influence of different rotary instruments such as Gates Glidden drills and other $\mathrm{Ni}-\mathrm{Ti}$ instruments for flaring on determination of $\mathrm{IAF}$, and ultrasonic tips are gaining popularity due to their superior visual access and control..$^{[5]}$

The present study aims to evaluate the influence of preflaring using rotary instruments and ultrasonic tip on apical file size determination.

\section{MATERIALS AND METHODS}

Atotal of 30intacthuman permanentmandibular first molars that are free of visible cracks, caries with complete root formation, and a degree of mesial root curvature in the range of $10-15$ were selected for the study. All teeth were ultrasonically cleaned to remove any surface debris and stored in $0.1 \%$ thymol solution at room temperature. Before $24 \mathrm{~h}$ of use, they were taken out and placed under tap water to eliminate traces of thymol. Once the teeth with standard root curvature between 10 and 15 were selected, standard access to pulp chamber was gained with endodontic access burs (Dentsply, Maillefer) and high-speed airotor handpiece (NSK, Japan) and the pulp tissue was removed with a barbed broach without contacting root canal walls. Canals were then irrigated with copious $2.5 \%$ sodium hypochlorite solution (Qualigens Fine Chemicals, Navi Mumbai, India). The root canal of each tooth was explored using a $08 \mathrm{~K}$-file until the apical foramen was reached and tip of the file was visible. The actual length for each tooth was determined and WL was established by deducting $1 \mathrm{~mm}$. Teeth were then washed and irrigated with normal saline to eliminate sodium hypochlorite residues. Teeth were randomly assigned into three groups.

Group-1: Control group - no preflaring was done. The size of IAF was determined without preflaring of the root canal.

Group-2: Rotary group - cervical portion of root canals was preflared with Protaper S1 and Sx (Dentsply) rotary files using endodontic electronic torque control Motor X-SMART (Dentsply), $4 \mathrm{~mm}$ short of the WL.

Group-3: Ultrasonic group - cervical portions of root canals were preflared with ET-18D diamond ultrasonic tip using woodpecker ultrasonic handpiece with short brushing strokes up to $4 \mathrm{~mm}$ short of WL.

All instruments were used according to the manufacturer's instructions with proper lubrication and irrigation. After preflaring, hand files were inserted into the mesiobuccal root canal, starting with K-file ISO 08/0.02 at the WL, and the file size was increased until slight friction was felt at WL. The first file that had a binding sensation at the WL was noted and fixed with methacrylate in the root canal. One millimeter of the root apex was cut horizontally with a microcutter so that the remaining tooth was at the WL. The apical sections were visualized using a stereomicroscope, and images were recorded digitally for each specimen [Figures 1 and 3].

Root canal and maximum file diameters were recorded for each sample at the WL. The differences between these measures were evaluated statistically by one variable test (ANOVA) followed by post hoc test.

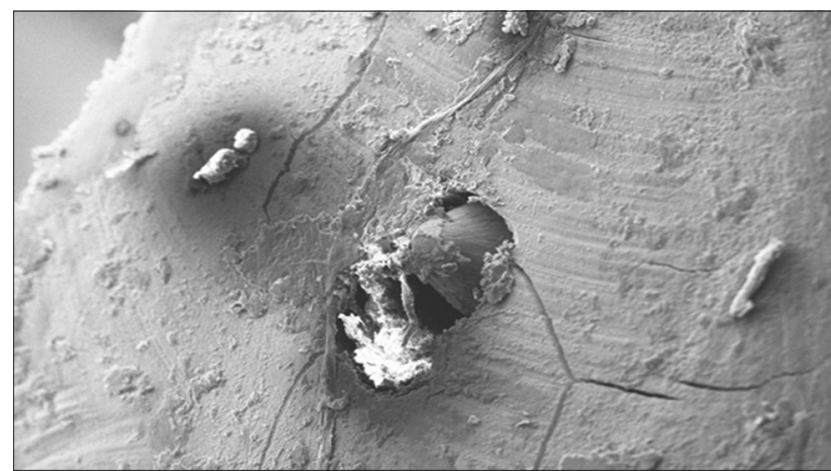

Figure 1: Scanning electron microscope micrograph of Group-1 showing no preflaring (cross-section at the working length with original 200)

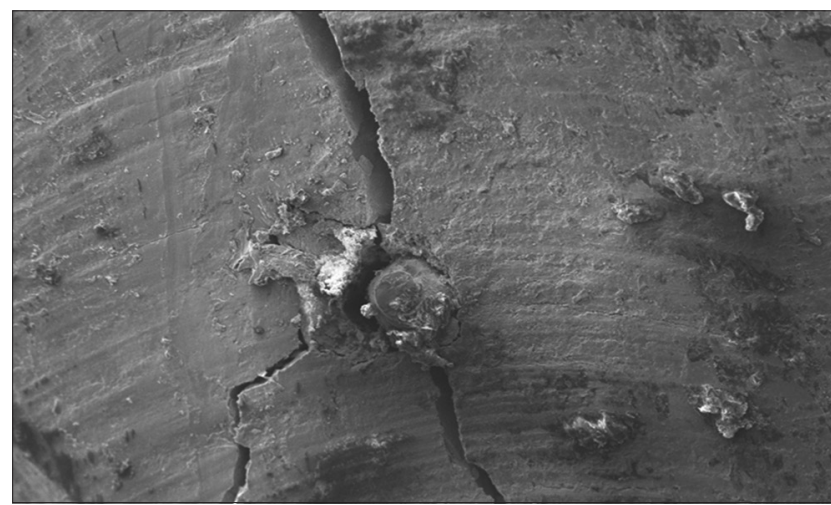

Figure 2: Scanning electron microscope micrograph of Group-2 (Protaper group) with preflaring done (cross-section at the working length with original 200) 


\section{RESULTS}

SPSS (version16) and Microsoft Excel software were used to carry out the statistical analysis of data. Mean and standard deviations were calculated. The differences between canal size and file diameter were noted, and the means and standard deviations are presented in Table 1. Comparison between the groups was made using the ANOVA test and pairwise comparison using the post hoc test is presented in Table $2, P<0.05$ was considered statistically significant. Major discrepancy was found in Group-1, where no preflaring was performed $(0.1016)$ and the ultrasonic tip produced smallest differences between anatomical diameter and first file to bind (0.0185 mean). Protaper instruments were ranked second with statistically significant results.

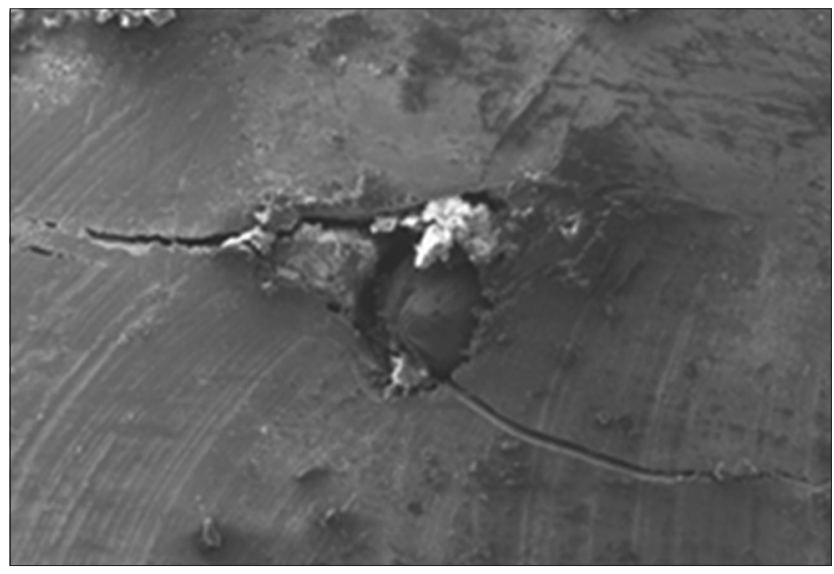

Figure 3: Scanning electron microscope micrograph of Group-3 (ultrasonic group) with preflaring done (cross-section at the working length with original 200)

Table 1: Comparison of discrepancies between the study groups

\begin{tabular}{lcccc}
$\begin{array}{l}\text { Study } \\
\text { groups }\end{array}$ & $\boldsymbol{n}$ & $\begin{array}{c}\text { Mean } \pm \text { Standard } \\
\text { deviation }\end{array}$ & F & Pvalue \\
\hline Group-1 & 10 & $0.1014 \pm 0.0071$ & 172.88 & $<0.001^{*}$ \\
Group-2 & 10 & $0.0371 \pm 0.0166$ & & \\
Group-3 & 10 & $0.0185 \pm 0.0077$ & & \\
\hline
\end{tabular}

* $P<0.05$ statistically significant, $P>0.05$, NS: Non-significant

Table 2: Pairwise comparison using post hoc Tukey test

\begin{tabular}{llllc} 
Group & \multicolumn{2}{c}{ Group } & P value & Inference \\
\hline Group-1 & Group-2 & 3.821 & $<0.001^{*}$ & $\mathrm{~S}$ \\
& Group-3 & 6.377 & $<0.001^{*}$ & \\
Group-2 & Group-3 & 2.556 & $<0.001^{*}$ & $\mathrm{~S}$
\end{tabular}

Tukey post hoc test, *: * $P<0.05$ statistically significant, $\mathrm{S}: P>0.05$, NS: Non-significant

\section{DISCUSSION}

In the course of cleaning and shaping of root canal system, the clinician must determine three clinical parameters. These are the length of canal, taper of the preparation, and working width. Working width (WW) is nothing but the horizontal dimension of root canal system at its most apical extent also referred to as IAF.

One standard method of deciding the size of apical preparation is to first determine the pre-operative canal diameter by passing consecutively larger instruments to the WL until one binds. Recent studies suggest that the first instrument that bound at WL did not accurately reflect the diameter of apical canal. ${ }^{[6]}$ This inaccuracy and discrepancy comes from various morphologic and procedural factors such as canal shape, canal length, curvature of the canal, coronal interference, and the instrument used in determination of initial working width. ${ }^{[1]}$ Hence, preflaring of the cervical and middle third region is recommended to eliminate interferences, to improve root canal preparation, and to promote a better quality of root canal treatment.

Early flaring regardless of the method used, removes interferences, opens the space, and reduces file contact in coronal and middle third region of canal, thus a file progresses more quickly toward the apex after flaring as previously suggested by Leeb. ${ }^{[4]}$ This better sense of apical diameter provides information that results in better control of biomechanical preparation. ${ }^{[7]}$ Preflaring of the cervical and middle third regions of root canal allows for a more accurate assessment of the real anatomical diameter of the apical constriction and more reliable determination of the IAF. ${ }^{[8]}$

In Group-1, in which IAF was determined without preflaring presented largest discrepancies between the canal size and the diameter of the file that bound at WL with a mean value of 0.1016 [Table 1] when compared to the other experimental groups.

From all the specimens evaluated, the root canals in Group-3, which were preflared with ultrasonic tips, were the best among all the three groups. They presented the least discrepancies between the canal size and the diameter of the first file that bound at the WL (mean 0.0185) followed by Group-2. This could be attributed as they are thinner tips which simultaneously cut overhangs and provide space for 
the debris to extrude coronally, which makes the file to reach apical third without any interferences. The visual access and superior control that ultrasonic cutting tips provide during access procedures make them the most convenient tool. ${ }^{[9,10]}$

Et-18D (Acetone) which is used in the Group-3, with an $18 \mathrm{~mm}$ tip length, used to remove dentinal overhangs and for refining access cavity. These have super-efficient cutting action; diamond-coated retro-tips abrade dentin more quickly using the side of the instrument rather than the chipping effect of uncoated instruments. This may help to minimize or prevent the incidence of cracking. ${ }^{[11-18]}$

In Group-2, Protaper gold rotary files S1 and Sx are used, which showed moderate results in this study. Verma et al. evaluated different instruments in producing a straight line access by cone-beam computed tomography, in which Protaper is less effective in reducing canal curvature and thus cannot produce better straight-line access.

As the interferences were eliminated with the flaring, files of greater sizes could be passively introduced into the canals until obtaining an instrument that bound at WL. The greater the removal of cervical interferences, the lesser the discrepancy between the canal diameter and the diameter of the binding file. These results are consistent with those of the previous studies using similar methodology. ${ }^{[9,12-20]}$

Based on the above results, regardless of the type of instrument used, it can be noted that any system used for preflaring is better than no system is used. Hence, to preflare the canal, before the initiation of cleaning and shaping of the root canal is a promising step to determine the working width appropriately.

\section{CONCLUSION}

Within the limitations of the present study, it can be concluded that both ultrasonic tip and Protaper rotary files can be used for preflaring to determine the IAF. ET-18D ultrasonic tip showed more promising results than Protaper rotary file as they removed canal irregularities effectively and presented lowest discrepancy values between the initial file size and anatomical apical diameter.

\section{REFERENCES}

1. Grossman LI, Oliet S, Rio DC. Preparation of the root canal: Equipment and technique for cleaning, shaping and irrigation. Endod Pract 1988;11:179-227.
2. Wu MK, Barkis D, Roris A, Wesselink PR. Does the first file to bind correspond to the diameter of the canal in the apical region? Int Endod J 2002;35:264-7.

3. Murthy SB, George JV, Kumar M. nfluence of coronal preflaring using gates Glidden and protaper instruments on the first apical file size determination- A comparative in vitro study. Journal of Endodontology 2008;5:30-4.

4. Leeb J. Canal orifice enlargement as related to biomechanical preparation. J Endod 1983;9:463-70.

5. Schmitz Mda S, Santos R, Capelli A, Jacobovitz M, Spanó JC, Pécora JD. Influence of cervical preflaring on determination of apical file size in mandibular molars: SEM analysis. Braz Dent J 2008;19:245-51

6. Jou YT, Karabucak B, Levin J, Liu D. Endodontic working width: Current concepts and techniques. Dent Clin North Am 2004;48:323-35.

7. Contreras MA, Zinman EH, Kaplan SK. Comparison of the first file that fits at the apex, before and after early flaring. J Endod 2001;27:113-6.

8. Pecora JD, Capelli A, Guerisoli DM, Spanó JC, Estrela C. Influence of cervical preflaring on apical file size determination. Int Endod J 2005;38:430-5.

9. Ibelli GS, Barroso JM, Capelli A, Spanó JC, PécoraJD. Influence of cervical preflaring on apical file size determination in maxillary lateral incisors. Braz Dent J 2007;18:102-6.

10. Plotino G, Pameijer CH, Grande NM, Somma F. Ultrasonics in endodontics: A review of the literature. J Endod 2007;33:81-95.

11. Gunes B, Aydinbelge HA. Effects of ultrasonic root-end cavity preparation with different surgical-tips and at different power-settings on glucose-leakage of root-end filling material. J Conserv Dent 2014;17:476-80.

12. Vanni JR, Santos R, Limongi O, Guerisoli DM, Capelli A, Pécora JD. Influence of cervical preflaring on determination of apical file size in maxillary molars: SEM analysis. Braz Dent J 2005;16:181-6.

13. Vasundhara S, Deepali A. Influence of cervical preflaring on apical file size determination - An in vitro study. Endodontology 2010;22:73-7.

14. Lin YH, Mickel AK, Jones JJ, Montagnese TA, González AF Evaluation of cutting efficiency of ultrasonic tips used in orthograde endodontic treatment. J Endod 2006;32:359-61.

15. Adorno CG, Yoshioka T, Suda H. The effect of root preparation technique and instrumentation length on the development of apical root cracks. J Endod 2009;35:389-92.

16. Tennert C, Herbert J, Altenburger MJ, Wrbas KT. The effect of cervical preflaring using different rotary nickel-titanium systems on the accuracy of apical file size determination. J Endod 2010;36:1669-72.

17. Kumar M, Kumar A, Mandal S, Kumar A, Gorka K, Kamal V. To determine whether the First File to bind at the Working Length corresponds to the Apical Diameter in Roots with Apical Curvatures both before and after Flaring using Two Rotary Systems: An in vitro Study. Int J Prev Clin Dent Res 2016;3:24-9 
18. Barroso JM, Guerisoli DM, Capelli A, Saquy PC, Pécora JD. Influence of cervical preflaring on determination of apical file size in maxillary premolars: SEM analysis. Braz Dent J 2005;16:30-4

19. Tan BT, Messer HH. The effect of instrument type and preflaring on apical file size determination. Int Endod $J$
2002;35:752-8.

20. Tambe VH, Nagmode PS, Vishwas JR, P SK, Angadi P, Ali FM. Evaluation of the amount of debris extruded apically by using conventional syringe, endovac and ultrasonic irrigation technique: An in vitro study. J Int Oral Health 2013;5:63-6. 